\title{
BASIC FITNESS TESTING OF RUGBY FOOTBALL PLAYERS
}

\author{
E. G. EVANS, D.P.E., M.Sc.
}

University College of Wales, Aberystwyth

\begin{abstract}
A revue of many of the books written on Rugby Football during the past $\mathbf{3 0}$ years reveal that a much greater emphasis is now being placed upon the role of fitness in the modern game. Much stress is being laid upon the physical requirements of the game so that qualities of muscular strength, muscular endurance, speed and stamina along with the accepted dominance of skill are becoming increasingly more accepted as being basic ingredients for the recipe of good play. More powerful team displays reflect an expression of these physical qualities. Coaches are becoming more aware of the fact that skill is influenced unfavourably by fatigue, the last learned technique tending to break down first under severe physical demands (Gray 1962). In order to prevent such breakdown the development of supreme physical fitness and match fitness is of paramount importance.
\end{abstract}

In the southern hemisphere the attainment of high standards of physical fitness for playing rugby football has always been viewed favourably and stressed as a playing attribute [Scott (1955), Travers (1955), Van Heerden (1966)]. Fortunately, a similar out-look is rapidly becoming accepted here in this country. Joynson (1965) when writing for schoolboys, rightly sees that "players must be very fit, fast and mobile, the concept of fitness must reach a new peak." In the same year, the most recent official publication for coaches of rugby football pinpointed the growing value of fitness for the sport. "There are four factors which the coach will try to influence; they are SKILL, SPEED, STRENGTH and STAMINA. These are very largely inter-related and concentration on one will will very often produce an improvement in another.... However, fitness is one of the games pre-requisites (Guide for Coaches 1965).

More recent authors refer to techniques designed to improve the basic qualities of muscular strength, muscular endurance, stamina (cardio-respiratory endurance), muscular power (explosive strength) and speed. Systems and methods are legion, the more advanced basing their practices upon the three fundamental theories of overload, specificity and reversibility (Faulkner 1968). Progressive coaches are prepared to adopt - and adapt - new, but proven training systems used in other sports (particularly those of track and field athletics, swimming and rowing) but little effort has been made to measure improvement in the acquisition of the physical attributes normally associated with rugby football.

\section{What kind of fitness are we concerned with?}

Most physiologists find that a single definition for physical fitness is difficult to accept, but perhaps the most appropriate one is that given by Morehouse and Miller (1963).

"The term fitness implies a relationship between the task to be performed and the individual's capability to perform it."

This definition is also more easily related to that of the W.H.O. (Technical Report Series No. 388) which defines Physical Fitness as the "ability to perform muscular work satisfactorily under specified conditions."

Both imply specificity. This fitness as applied to Rugby players depends upon the suitability of the individual's body structure to perform the task, the effectiveness with which his organs and systems support the effort of playing, and finally the attitude he adopts in approaching the task demanded of him.

\section{What are these tasks demanded of him?}

The forward is required to hold the push in the scrum, give an explosive push when the ball is put in, jump in the lineout and search and work for the ball in the loose maul. In addition, he must, during his roaming of the field, be prepared to explode into tackles, dive, fall and pick up the ball and make bursts of speed in support of developing attacks. The back, in contrast, is expected to make longer bursts of speed, change direction at speed, crash tackle, kick, chase as well as produce perfect passes under the threat of imminent tackles. If one was to analyse these movements, it would immediately be evident that the basis of most of them is sheer muscular power - strength being applied at speed (explosive strength) whether it be leg strength, back strength, shoulder strength or the combination of all three. Furthermore, these movements are required to be repeated countless times in the process of the game, repetition which makes high demands on muscular and cardio-respiratory endurance. It is imperative then, that one develops strength in the legs, lower back, arms and shoulder girdle in order to carry out the powerful movement required during the course of a game, and to withstand the hard body contact encountered in it. The 
development of this strength, plus stamina and flexibility also provides a safeguard against injury.

If one applies a stop watch to record the time that play actually continues without interruption it will be found that a continuous playing period of 30 secs. is rarely achieved. Between 15-20 secs. appears to be the average period of uninterrupted play. Such short periods of intense activity - by forwards only for the greater part of this time - is indicative of anaerobic type energy expenditure since brief periods of work involving maximum efforts lasting less than $1 \mathrm{~min}$. are largely dependent upon anaerobic capacity and power.

\section{Fitness components and Test Selection}

Although a single test of physical fitness is not available, many tests have been developed which measure components of fitness. None of the established short physical performance test batteries will measure adequately all the components, but this does not mean that they are without value. It is particularly difficult to select tests which will directly measure the fitness of an athlete for his particular event unless one performs the event itself. However, once having identified the physical elements which are considered essential and worth acquiring for playing better rugby football, and with careful scrutiny of the literature bearing in mind the practical difficulties normally associated with physical performance testing, suitable tests can be selected with confidence. The following test items have, over the past six years, shown themselves to have merit in testing the basic physical qualities identified, and are suggested as suitable for testing the relative physical fitness standards of rugby players.

\section{Test Item \\ 1. Parallel Bar Dips \\ 2. Pull Up \\ 3. Arm Strength Index}

4. Vertical Jump

5. Shuttle Run (5 $\times 20$ yards)

6. Leg Lifts (in 30 secs.)

7. Grip Strength (Dominant Hand)

8. Back Lift

9. 600 yards Run

\section{Element Measured}

Muscular Endurance

Upper body strength in relation to height and weight

Muscular Power (Explosive Strength)

Trunk Strength

Hand, forearm and general strength

Lumbar and general strength Fast running endurance
These tests are well documented and require no further explanation other than items 1, 2, 3, 7 and 8 are scored according to Rogers Strength Index, the Vertical Jump administered in the manner suggested by Morgan and Adamson, and the Shuttle Run, Leg Lift and 600 yard Run tests implemented in the manner designed by
Edwin Fleishman. All items are fully described in Campbell and Tucker's text (1967). The 600 yard Run, initially introduced as an estimate of aerobic power, is now viewed as a measure of fast running endurance. Astrand and Rodahl (1970) have suggested that a maximal effort expended over a 2 minute period draws upon approximately a balance of $50 \%$ anaerobic energy. However, it is accepted that different individuals, depending upon the relative capacity of the two energy stores, can shift the emphasis of their energy output to extract the maximum benefit of their natural and trained capacities.

It would appear, on reflection, that the suggested battery of tests is deficient in a true measure of aerobic capacity. This element of physical fitness could be measured by either applying one of the accepted step tests or introducing a longer run based on the Cooper 12 mins. Run Test (1970) or the ICSPFT 2000 metre run.

\section{NORMS}

The following norms have been compiled from data collected over the past 6 years from two sources,

a) Players attending Rugby Coaching Courses at the University College of Wales, Aberystwyth under the auspices of the W.R.U. and Sports Council (then C.C.P.R.)

b) In the case of adult players, from testing sessions conducted at club venues or at U.C.W. Aberystwyth.

A previous presentation (Evans 1968) pinpointed the significant differences which exist between forwards and backs at youth level, namely that forwards are taller, heavier and stronger in back and grip strength than the backs who are significantly superior in explosive strength as depicted by the suggested tests. Test inter-relationships were displayed in the previous work, but it will be noted that an Arm Strength Index has been introduced to minimise the differences in height and weight.

Table I presenting the means of the various selected playing populations reflects a tendancy for scores to improve as one grows older, and where first class playing standard is defined. Norms for the adult population, Table II, are drawn from Cardiff, Llanelli and Monmouthshire players with a small percentage $(9 \%)$ of local Aberystwyth players. Youth norms are drawn from selected players' courses (Welsh National Youth and Secondary Schools Players) and open courses, but not published in this short article. ${ }^{*}$

It is well to remember that although exercise tests do not evaluate a subject's response to emotional and environmental factors that can influence performance 
TABLE I

PHYSICAL FITNESS PROFILE OF ADULT WELSH RUGBY PLAYERS - FORWARDS \& BACKS

${ }^{*}$ Copies of these tables can be obtained by application to the author.

\begin{tabular}{|c|c|c|c|c|c|c|c|c|c|}
\hline $\begin{array}{l}\text { fige } \\
\text { Group }\end{array}$ & $\begin{array}{l}\text { Bar } \\
\text { Dips }\end{array}$ & Pulp & $\underset{\text { Strength }}{\text { Arm }}$ & $\begin{array}{l}\text { Vertical } \\
\text { Jump }\end{array}$ & $\begin{array}{l}\text { Shuttle } \\
\text { Bun }\end{array}$ & $\begin{array}{l}\text { Iog } \\
\text { Iffts }\end{array}$ & $\begin{array}{l}\text { Grip } \\
\text { Strength }\end{array}$ & $\begin{array}{l}\text { Back } \\
\text { IIft }\end{array}$ & $\begin{array}{l}600 \text { yds. } \\
\text { Run }\end{array}$ \\
\hline $15=17$ & & & & & & & & & \\
\hline BACKS & 13.8 & 7.63 & 469.5 & 21.25 & 19.31 & 20.21 & 107.6 & 379.3 & 100.2 \\
\hline FCRLAARDS & 9.92 & 5.73 & 391.5 & 20.71 & 20.07 & 19.36 & 118.7 & 430.0 & 103.6 \\
\hline \multicolumn{10}{|l|}{$17=19$} \\
\hline BACKS & 16.84 & 7.96 & 591.2 & 22.19 & 18.99 & 21.57 & 112.0 & 41402 & 97.67 \\
\hline FORKLARDS & 12.88 & 5.68 & 516.7 & 21.77 & 19.76 & 20.82 & 121.7 & 458.1 & 100.4 \\
\hline \multicolumn{10}{|l|}{ ADULTS } \\
\hline BACKS & 17.76 & 8.54 & 689.59 & 23.98 & 18.9 & 26.24 & 128.04 & 481.67 & 86.75 \\
\hline FORWARDS & 14.85 & 5.28 & 694094 & 23.03 & 19.58 & 23.53 & 146.82 & 563.45 & 98.72 \\
\hline
\end{tabular}

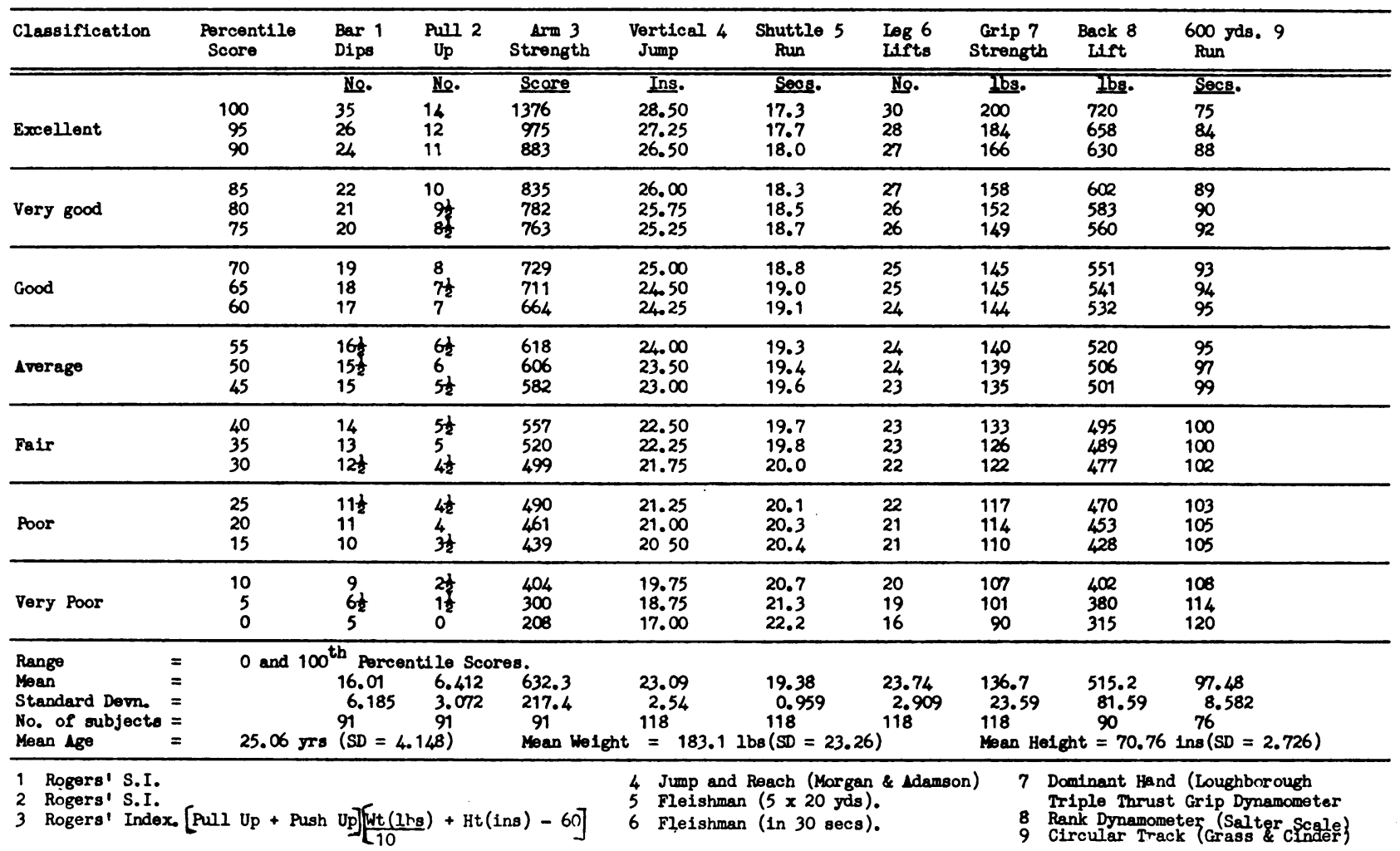

TABLE // is a sample of the score sheet used to work out the fitness profiles of adult players. Similar score sheets with the percentile score suitably adjusted have been calculated for Forwards aged 17-19, Backs 17-19, Forwards aged $15-17$, Backs $15-17$, but these are not illustrated in this article. 
they provide an objective measurement of some of the elements normally identified with physical fitness for sports participation under test conditions. It is suggested that if a testing programme is implemented a greater interest in acquiring higher fitness levels will result. Rugby football skill is not measured, but it is assumed that a fitter skilful player is more of an asset to his team or club than an unfit player, always remembering that when fatigue sets in skill deteriorates. Thus it is the duty of every player to aim for a fitness standard which will carry him through the rigours of a strenuous game and more. It is believed that pursuance of a measurement programme in conjunction with general coaching and fitness training will help to objectively achieve this aim.

It would be foolish to conclude without holding a certain reservation regarding the application of fitness attributes to Rugby Football. This I feel was best expressed by G. S. Conway back in 1922 when writing in "Notes on Rugby Football." - "Now it is obvious that skill in rugger depends not on the possession of physical qualities but upon the intelligent use of them."

\section{REFERENCES}

1. ÅstRAND, P. O. "Textbook of Work Physiology", McGraw Hill, 1970.

2. CAMPBELL, W. R. and TUCKER, N. M. "An introduction to tests and measurements in physical education." Bell, London 1967.

3. CONWAY, G. S. "Notes on rugby football." Cambridge Review New Blue Series No. 2. 1922.

4. COOPER, K. "New Aerobics." Bantam Books, 1970.

5. EVANS, E. G. "Fitness scores of Welsh Youth rugby football players." Brit.J. of Sports Med. 4 60-62, 1969.

6. FAULKNER, J. A. “New perspectives in Fitness Training.” J.A.M.A., Sept. 1968.

7. FLEISHMAN, E. A. "The structure and measurement of physical fitness." Prentice-Hall, 1964.

8. GRAY, R. K. "Repetitive practice in motor learning." Physical Education 54 No. 162. July, 1962.

9. JOYNSON, D. C. "Better Rugby for Boys." Nicholas Kaye, London, 1965.

10. MOREHOUSE and MILLER A. T. "Physiology of Exercise." 4th Edn. C. V. Mosby and Co. St. Louis 1963.

11. MORGAN and ADAMSON, G. "Circuit Training." Bell, London.

12. R. F. U. "Guide for Coaches." Pamphlet VIII, p 2., 1965.

13. SCOTT, R. W. H. and McLEAN, T. P. "Bob Scott on Rugby." Nicholas Kaye London, 1955.

14. STUART, I. M. B. "The Theory of Modern Rugby Football." MacMillan and Co. Ltd., London, 1930.

15. TRAVERS, B. H. "How to Play Rugger." Eyre and Spottiswoode, 3rd Ed. London, 1955.

16. VAN HEERDEN, I. “Coaching, Practising and Training for Tries." Drabensburg Press Ltd. Durban, 1966.

17. W. H. O. "Exercise Tests in relation to Cardio-Vascular Function." Technical Report Series No. 388. 1968. 